\title{
A Novel Secretory Factor, Neurogenesin-1, Provides Neurogenic Environmental Cues for Neural Stem Cells in the Adult Hippocampus
}

\author{
Takatoshi Ueki, ${ }^{1}$ Masamitsu Tanaka, ${ }^{2,4}$ Kanna Yamashita, ${ }^{1}$ Sumiko Mikawa, ${ }^{1}$ ZheFu Qiu, ${ }^{1}$ Nicholas J. Maragakis, ${ }^{5}$ \\ Robert F. Hevner, ${ }^{6}$ Naoyuki Miura, ${ }^{3}$ Haruhiko Sugimura, ${ }^{2}$ and Kohji Sato ${ }^{1}$ \\ ${ }^{1}$ Department of Anatomy and Neuroscience, ${ }^{2}$ First Department of Pathology, and ${ }^{3}$ Department of Biochemistry, Hamamatsu University School of Medicine, \\ Hamamatsu, Shizuoka 431-3192, Japan, ${ }^{4}$ Growth Factor Division, National Cancer Center Research Institute, Chuo-ku, Tokyo 104-0045, Japan, \\ ${ }^{5}$ Department of Neurology, Johns Hopkins University School of Medicine, Baltimore, Maryland 21287, and 'Department of Pathology, University of \\ Washington School of Medicine, Seattle, Washington 98104
}

Neurogenesis occurs in restricted regions in the adult mammalian brain, among which the neurogenesis in the hippocampal dentate gyrus plays the crucial role in learning and memory. To date, little is known about neurogenic cues, which result in the neuronal fate adoption of neural stem cells residing in neurogenic regions, especially neurogenic cues in adult hippocampal neurogenesis. In the present study, we show that hippocampal astrocytes and also dentate granule cells adjacent to neural stem cells secrete a newly cloned novel secretory factor, Neurogenesin-1. This protein contains three cysteine-rich domains and a unique sequence and contributes to neuronal differentiation of neural stem cells in the adult brain by preventing the adoption of a glial fate. Furthermore, the neurogenic activity detected in the hippocampal culture medium was markedly suppressed by the administration of an anti-Neurogenesin-1 antibody. These findings suggest endogenous mechanisms that induce adult hippocampal neurogenesis and propose an innovative treatment for the neurodegenerative diseases that cause loss of hippocampal neurons.

Key words: Neurogenesin-1; astrocyte; neural stem cell; rat; hippocampus; neurogenesis; neurogenic cues

\section{Introduction}

It is well established that neurogenesis occurs throughout development in the adult mammalian brain; however, it is restricted to specific regions: the subventricular zone and the hippocampal dentate gyrus (Fujita, 1986; Gage, 2000). The previous in vitro isolation and graft experiments of neural stem cells showed the potential to differentiate toward neurons and glia, but in in vivo neurogenic regions, neuronal fate commitment is the predominant pathway. Recent studies confirmed the involvement of several basic helix-loop-helix (bHLH) transcription factors in neuronal fate determination of neural stem cells. These bHLH transcription factors include neurogenin 1 and 2, Mash1, and Math1 (Guillemot et al., 1993; Ma et al., 1996; Ben-Arie et al., 1997; Fode et al., 1998; Sun et al., 2001). However, the neurogenic environmental cues that result in neurogenesis in some restricted regions remain to be elucidated. Recent data revealed that ependymal cells adjacent to the subventricular zone were implicated in neurogenesis (Lim et al., 2000); however, to date, the neurogenic cues, especially in the adult hippocampal dentate gy-

\footnotetext{
Received May 26, 2003; revised 0ct. 21, 2003; accepted 0ct. 22, 2003.

We thank Drs. Heinrich Betz, Hermann Rohrer, Shigeyoshi Itohara, Taiji Kato, Asami Tsuchiya, Mayumi Tokunaga, and Makiko Suzuki for comments or discussions that improved this manuscript.

Correspondence should be addressed to Kohji Sato, Department of Anatomy and Neuroscience, Hamamatsu University School of Medicine, 1-20-1 Handayama, Hamamatsu, Shizuoka 431-3192, Japan. E-mail: ksato@hamamed.ac.jp.

Copyright $\odot 2003$ Society for Neuroscience $\quad 0270-6474 / 03 / 2311732-09 \$ 15.00 / 0$
}

rus, which is considered to be crucial for learning and memory (Gould et al., 1999), are less understood.

Previous studies have demonstrated that bone morphogenetic proteins (BMPs) alter the fate of neural stem cells from neurogenesis to astrocytogenesis by upregulating the expression of the negative HLH factors Id1, Id3, and Hes5 (Gross et al., 1996; Nakashima et al., 2001; Yanagisawa et al., 2001). Additional observations that BMPs and their receptors are continuously expressed in the adult brain (Soderstrom et al., 1996; Ebendal et al., 1998; Charytoniuk et al., 2000) led us to the notion that BMPs may be involved in adult neurogenesis. The BMP antagonists that bind to BMPs and consequently prevent activation of BMP receptors (Sasai et al., 1995; Sasai, 2001) are the potential molecules that direct neural fate commitment of neural stem cells and can provide neurogenic cues for neural stem cells in the adult brain. Astrocytes residing in the neurogenic regions are one of the possible sources for providing such cues.

In the present study, we show that astrocytes mainly secrete a novel secretory factor, Neurogenesin-1 (Ng1), and are involved in adult neurogenesis. $\mathrm{Ng} 1$ was composed of three cysteine-rich domains characteristic of BMP antagonists and the following unique segments. Ng1 mRNA was intensely expressed in the hippocampus and moderately around the lateral ventricle in the adult brain. Immunohistochemistry revealed that astrocytes in the hippocampal dentate gyrus abundantly secreted Ng1. It was also observed that dentate granule cells considerably expressed 


\section{a}

MFFLPPTFESPLPLRAHSSSRHNLRAPDLGGAPQGAQSVCKRGRRKRPVP

SFSPPVLGVSELHFAVAQRRREWKMWGIKYIASL VFFFVFLEASKTEPVK

100

HSETYCMFODKKYRVGEKWHPYLEPYGLVYCVNCICSENGNVLCSRVRCP

TLHCLSPVHIPHLCCPRCPDSLPPMNSKVTSKSCEYNGTTYOHGELFIAE

GLFQNRQPNQCSQCSCSEGNVYCGLKTCPKLTCAFPVSVPDSCCRVCRGD

GELSWEHSDADIFRQPANREARHSYLRSPYDPPPSRQAGGLPRFAGSRSH

300

RGAVIDSQQASGTIVQIVINNKHKHGQVCVSNGKTYSHGESWHPNLRAFG

IVECVLCTCNVTKOECKKIHCPNRYPCKYPQKLDGKCCKVCPEEPPSQNF

DSKGSFCGEETMPVYEAVLVEDGETARKVALETEKPPQVEVHVWTIRKGI

LQHFHIEKISKEMFGGLHHFKLVTRTTMNQWKIFAEGEAQLSQMCSSRVC

500

RTELEDLVQVLYLERPEKDHC

\begin{tabular}{|c|c|c|c|}
\hline $\mathrm{Ng}^{1} \mathrm{SP}$ & CR1 & CR2 & CR3 \\
\hline
\end{tabular}

b

Ng1 CR1 CMFQDK-KYRV-GEKWHP-YLEPYGLVYCVNCICSEN-GNVLCSRVRCPTLH-CLSPVHIPHL-CCPRCP

Ng1 CR2 CEYNGT-TYQH-GELFIAEGLFQNRQPNQCSQCSCSE-GNVYCGLKTCPKLT-CAFPVSVPDS-CCRVCR

Ng1 CR3 CVSNGK-TYSH-GESWHP-NLRAFGIVECVLCTCNVTKQ-ECKKIHCPNRYPCKYPQKLDGK-CCKVCP

Chd CR3 CYFDGDRSWRAAGTRWHP-VVPPFGLIKCAVCTCKGATGEVHCEKVQCPRLA-CAQPVRANPTDCCKQCP

\section{C}

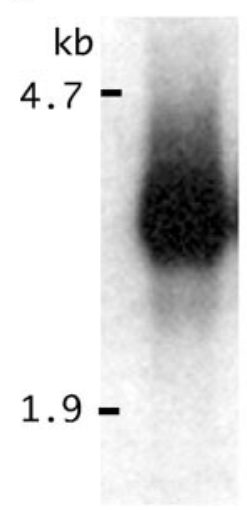

Figure 1. a, The amino acid sequences and structure of newly cloned $\mathrm{Ng} 1$. The italics in the $\mathrm{N}$ terminus stand for the putative signal peptide. The underlined sequences indicate the three cysteine-rich domains. The first and third cysteine-rich domains contained BMP-binding modules (amino acid sequences, WHP). In the schema of the structure, SP indicates signal peptide and CR indicates cysteine-rich domains. $b$, The comparison of CR found in $\mathrm{Ng} 1$ and chordin (Chd). The third cysteine-rich domain (CR3) of Chd showed a similarity in sharing three cysteine-rich domains (CR1-CR3). The underlined letters indicate the identical sequences in cysteine-rich domains. C, Northern blot analysis revealed a $3.9 \mathrm{~kb}$ transcript and intense expression of $\mathrm{Ng} 1$ in astrocytes of the adult hippocampus.

$\mathrm{Ng} 1$. These patterns of $\mathrm{Ng} 1$ expression demonstrate that $\mathrm{Ng} 1$ plays a key role in adult hippocampal neurogenesis.

Additional experiments showed that the supernatant of dissociated hippocampal cultures resulted in the neuronal fate adoption of neural stem cells, and that anti-Ng1 antibody blocked such neurogenic activities. These data suggest that the hippocampus secretes the soluble neuronal determinant and implicate the endogenous expression of $\mathrm{Ng} 1$ as a neurogenic cue.

Together, the results of this study demonstrate that astrocytes and some neighboring neurons residing in neurogenic regions of the adult brain, especially in the hippocampal dentate gyrus, se- crete a newly cloned secretory factor, $\mathrm{Ng} 1$, and contribute to provide neurogenic cues for neural stem cells. Our findings may shed light on endogenous neurogenic cues in adult neurogenesis that were ignored previously.

\section{Materials and Methods}

Astrocyte culture. Astrocyte cultures were primarily cultured from the adult Wistar rat hippocampi, as described previously (Banker and Cowan, 1977; Ueki et al., 1993). Astrocytes were grown to confluence and maintained in passage in DMEM low glucose (Invitrogen, Carlsbad, CA) containing $10 \%$ fetal bovine serum (FBS) and penicillin-streptomycin until use.

Cloning of $\mathrm{Ng} 1 \mathrm{cDNA}$. The total RNA was isolated from adult Wistar rat hippocampal astrocyte cultures using Isogen (Nippon Gene, Tokyo, Japan), and subsequently, reverse transcripts were prepared using True Script II reverse transcriptase (Sawady, Tokyo, Japan). The synthesized cDNA was subjected to the degenerate PCR in a low stringency. The primers contained the sequences coding BMP-binding modules and the adjacent sequences found in chordin. The primer pairs used were as follows: sense primer 5' -GGWGAGNNTGGCACCC-3' and antisense primer $5^{\prime}$-GGGTGCCANNKCTCWCC-3'. The synthesized DNA was elongated using a GeneRacer rapid amplification of cDNA ends (RACE) kit (Invitrogen) in accordance with the protocol of the manufacturer. The sequence of isolated cDNA was analyzed using a DYEnamic ET terminator cycle sequencing kit (Amersham Biosciences, Little Chalfont, UK) and ABI Prism 310 genetic analyzer (Applied Biosystems, Foster City, CA).

Northern blotting. Northern blot analysis was performed as described previously (Ueki et al., 2001). Briefly, $10 \mu \mathrm{g}$ of total RNA prepared from astrocyte culture of the adult rat hippocampus was separated electrophoretically and blotted onto the nylon membrane (Osmonics, Minnetonka, MN). The cDNA coding Ng1 was labeled with $\left[\alpha^{-}{ }^{32} \mathrm{P}\right]$ deoxy-CTP (PerkinElmer Life Sciences, Boston, MA) using the Megaprime DNA labeling system (Amersham Biosciences), and the hybridized membrane was exposed to $\mathrm{x}$-ray film.

Microinjection of Ng1 mRNA to Xenopus embryos. Fertilized embryos were prepared as described previously (Newport and Kirschner, 1982). Capped synthetic mRNAs were generated by in vitro transcription of linearized pCS2 + vectors with the inserts as described previously, and RNA was microinjected according to published procedures (Tanaka et al., 1998). Embryos were fixed in $0.1 \mathrm{M}$ morpholinopropane sulfonic acid , 2 mM EGTA, $1 \mathrm{~mm}$ $\mathrm{MgSO}_{4}$, and 3.7\% formaldehyde for $1 \mathrm{hr}$, embedded in plastic according to the instructions of the manufacturer (JB-4; Polysciences, Warrington, PA), and sectioned at $5 \mu \mathrm{m}$. Sectioned tissue was stained with hematoxylin and eosin.

In situ hybridization. Male Wistar rats at various ages [embryonic day 17 (E17) and postnatal day 1 (P1), P7, P14, and P49; $n=3$ at each time point] were decapitated under diethylether anesthesia. The fresh brains were quickly removed and immediately frozen on powdered dry ice. Serial sections ( $20 \mu \mathrm{m}$ thick) were cut on a cryostat, thaw-mounted onto 
silan-coated slides, and stored at $-80^{\circ} \mathrm{C}$. After being warmed to room temperature, slidemounted sections were fixed in $4 \%$ paraformaldehyde in $0.1 \mathrm{~m}$ phosphate buffer (PB), $\mathrm{pH} 7.2$, for $15 \mathrm{~min}$ (all steps were performed at room temperature unless otherwise indicated), rinsed three times ( 5 min each) in $4 \times$ SSC, pH 7.2 ( $1 \times$ SSC contains $0.15 \mathrm{~m}$ sodium chloride and 0.015 M sodium citrate), and dehydrated through a graded ethanol series (70-100\%). The sections were then defatted with chloroform for $5 \mathrm{~min}$ and immersed in 100\% ethanol (twice for $5 \mathrm{~min}$ each time) before being subjected to hybridization. Hybridization was performed by incubating the sections with a buffer [ $4 \times$ SSC, $50 \%$ deionized formamide, $0.12 \mathrm{M}$ phosphate buffer, $\mathrm{pH} 7.2$, Denhardt's solution (Nacalai Tesque, Kyoto, Japan), 0.025\% tRNA (Roche Products, Basel, Switzerland), and $10 \%$ dextran sulfate (Sigma, St. Louis, MO)] containing $\left[{ }^{35} \mathrm{~S}\right]$ deoxy-ATP (dATP) [1000-1500 Ci/mmol (37-55.5 TBq/mmol); NEN, Boston, MA]-labeled probes $\left(1-2 \times 10^{7}\right.$ $\mathrm{dpm} / \mathrm{ml}, 0.2 \mathrm{ml} / \mathrm{slides}$ ) for $24 \mathrm{hr}$ at $41^{\circ} \mathrm{C}$. After hybridization, the sections were rinsed in $1 \times$ SSC, $\mathrm{pH}$ 7.2, for $10 \mathrm{~min}$, followed by rinsing three times in $1 \times \mathrm{SSC}$ at $55^{\circ} \mathrm{C}$ for $20 \mathrm{~min}$ each time. The sections were then dehydrated through a graded ethanol series (70-100\%). After film exposure for $3 \mathrm{~d}$ at room temperature, the sections were coated with Kodak NBT-2 emulsion (Eastman Kodak, Rochester, NY) and diluted 1:1 with water. The sections were then exposed at $4^{\circ} \mathrm{C}$ for $2-4$ weeks in a tightly sealed dark box. After being developed in D-19 developer (Eastman Kodak), fixed with photographic fixer, and washed with tap water, the sections were counterstained with thionin solution to allow morphological identification. Antisense oligo cDNA probes for detecting $\mathrm{Ng} 1$ mRNA were as follows: antisense 1 (AS1), 5' -TTGACTTTGGGGTTTTGGAGCACTGTTGACTTAAGT-3' and AS2, 5' -TCGCACCACGAGGGAGCAGAGGCTCGCTTGGCTCCA-3'.

The specificity of the probes has been confirmed using control experiments, as shown in our previous study (Kanaka et al., 2001). The probes were labeled at the $3^{\prime}$ end using $\left[{ }^{35} \mathrm{~S}\right] \mathrm{dATP} \quad[1000-1500 \mathrm{Ci} / \mathrm{mmol} \quad(37-55.5$ $\mathrm{TBq} / \mathrm{mmol}$ ); PerkinElmer Life Sciences] and terminal deoxynucleotidyl transferase (Takara, Otsu, Japan) to obtain a specific activity of $\sim 1.4-$ $2.0 \times 10^{9} \mathrm{dpm} / \mathrm{mg}$.

Immunohistochemistry and preparation of anti-Ng1 antibody. Cryosections ( $20 \mu \mathrm{m}$ thick) of the adult rat brain were mounted on poly-L-lysinecoated glass and fixed in $4 \%$ paraformaldehyde in $0.1 \mathrm{M} \mathrm{PB}, \mathrm{pH} 7.2$, for 20 $\min$ at $4^{\circ} \mathrm{C}$. The sections were then treated with $10 \%$ normal goat serum, $2 \%$ bovine serum albumin, and $0.2 \%$ Triton $\mathrm{X}-100$ in $0.1 \mathrm{M} \mathrm{PB}, \mathrm{pH} 7.2$, for $20 \mathrm{~min}$ at room temperature and incubated further in anti-Ng1 (1: $100)$ and anti-glial fibrillary acidic protein (GFAP) (1:800; Chemicon, Temecula, CA), anti-neuron-specific enolase (NSE) (1:800; Chemicon), and anti-myelin proteolipid protein (PLP) (1:100; Chemicon) antibodies. After washing, sections were incubated in Alexa Fluor 546 anti-rabbit IgG (1:2000; Molecular Probes, Eugene, OR) and Alexa Fluor 488 antimouse IgG (1:1000; Molecular Probes). Anti-Ng1 antibody was prepared according to ordinary methods described previously. KLH-conjugated oligopeptides LERPEKDHC (513-521) were immunized against New Zealand White rabbits followed by bleeding out. Antiserum was purified by CM Affi-Gel blue gel (Bio-Rad, Hercules, CA). The adult hippocampal astrocytes were homogenized and subjected to Western blotting with
anti-Ng1 antibody. The antibody was certified by an $\sim 50 \mathrm{kDa}$ single band (data not shown).

Neural stem cell culture and cell typing. Neural stem cells were primarily cultured from the P14 or P35 Wistar rat hippocampus. The hippocampus was dissected and mechanically dissociated by Pasteur pipette. Dissociated cells were incubated for $3 \mathrm{~d}$ in a poly-L-lysine-coated 24 well plate (Sumitomo Bakelite, Tokyo, Japan) in DMEM-F12 (Invitrogen) containing an $\mathrm{N}-2$ supplement (Invitrogen) and $20 \mathrm{ng} / \mathrm{ml}$ human recombinant basic fibroblast growth factor (bFGF) (Genzyme Techne, Cambridge, MA). Cells were maintained in passage and then transferred to a poly-L-lysine-coated $13.5 \mathrm{~mm}$ coverslip (Sumitomo Bakelite) laid in a $500 \mu \mathrm{l}$ medium-filled well with a density of $5 \times 10^{2}$ cells $/ \mathrm{ml}$ for the examination. The cells were

\section{Table 1. Summary of secondary axis formation in microinjected embryos}

\begin{tabular}{lllc}
\hline $\begin{array}{l}\text { Sample } \\
\text { injected }\end{array}$ & $\begin{array}{l}\text { Nanograms of RNA } \\
\text { per embryo }\end{array}$ & $\begin{array}{l}\text { Secondary dorsal axis/number } \\
\text { of surviving }^{a}\end{array}$ & $\begin{array}{l}\text { Number of embryos } \\
\text { injected }\end{array}$ \\
\hline $\mathrm{Ng} 1$ & 0.8 & $23 / 81(28 \%)$ & 95 \\
$\mathrm{Ng} 1$ & 1.6 & $68 / 114(60 \%)$ & 134 \\
Water & 0 & $0 / 106(0 \%)$ & 112 \\
\hline
\end{tabular}

${ }^{a}$ The phenotypes of the injected embryos were scored morphologically at stages $36-41$. 

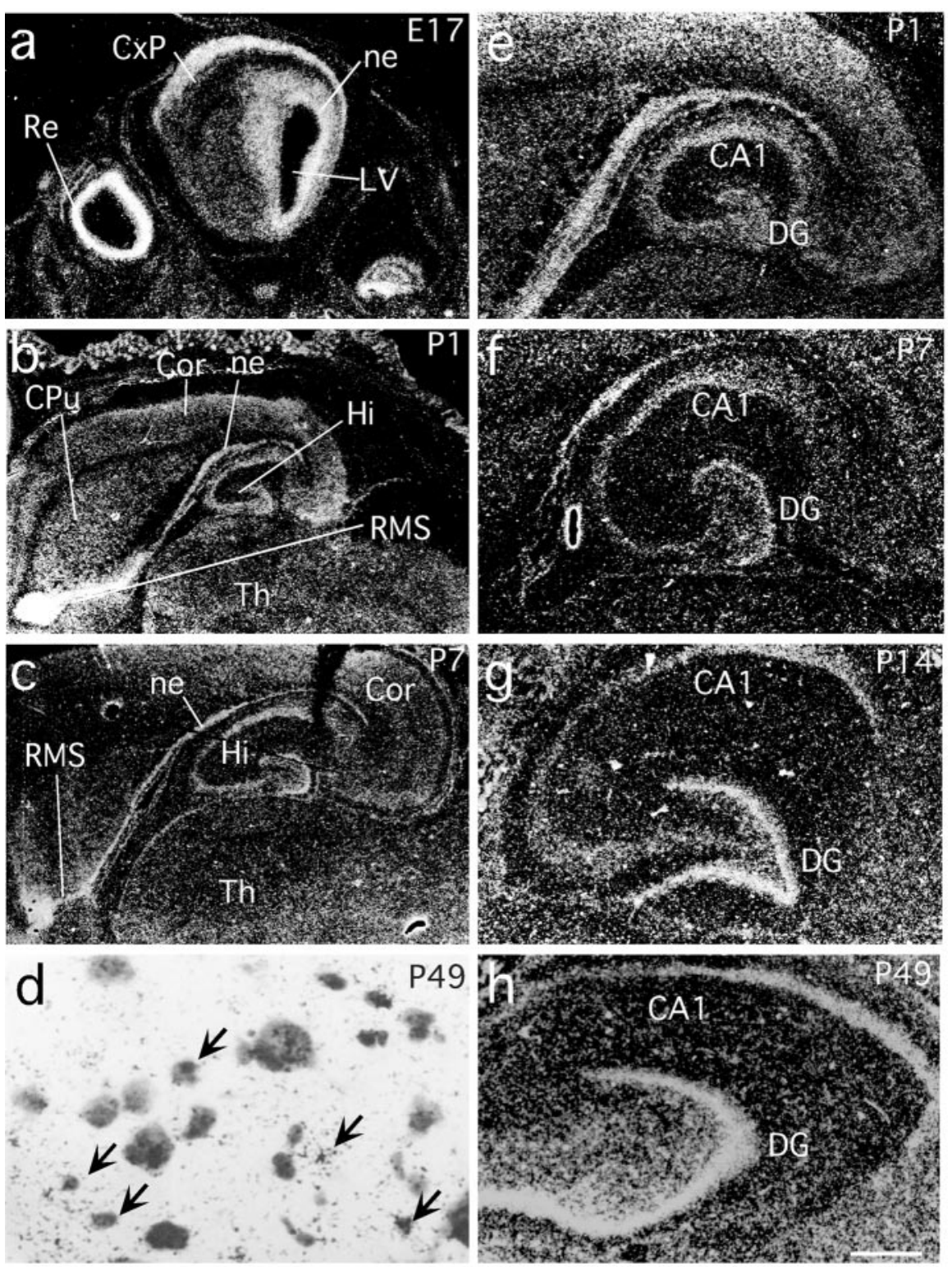

Figure 3. The expression pattern of $\mathrm{Ng} 1 \mathrm{mRNA}$ in brains throughout development. $a$, The expression of $\mathrm{Ng} 1 \mathrm{on} \mathrm{E} 17 . b, c$, The expression of $\mathrm{Ng} 1$ in the neurogenic regions on $\mathrm{P} 1(b)$ and $\mathrm{P} 7$ ( $c$ ). $d$, Bright-field photomicrograph showing Ng1 mRNA expression in the adult cerebral cortex; note that small-sized cells (arrows) are covered with hybridization signals. $e-h$, The abundant expression of $\mathrm{Ng} 1$ in the hippocampal dentate gyrus on P1, P7, P14, and P49. CA1, Field CA1 of Ammon's horn; CxP, cortical plate; ne, neuroepithelium; LV, lateral ventricle; Re, retina; Cor, cerebral cortex; Hi, hippocampus; RMS, rostral migratory stream; $\mathrm{CPu}$ caudate putamen; Th, thalamus; DG, dentate gyrus. Scale bars: $a-c, 500 \mu \mathrm{m} ; d, 50 \mu \mathrm{m} ; e-h, 200 \mu \mathrm{m}$.

incubated further for $24 \mathrm{hr}$ until use. Finally, nearly all of the cells $(>95 \%)$ were nestin-positive neural stem cells (data not shown). To examine the fate commitment of neural stem cells, cells were incubated for $4 \mathrm{~d}$ in DMEM-F12 containing the stimulant. For the cell typing, cells were fixed in $4 \%$ paraformaldehyde in $\mathrm{PB}, \mathrm{pH} 7.2$, for $30 \mathrm{~min}$ at $4^{\circ} \mathrm{C}$ and treated for permeation in $0.5 \%$ Triton $\mathrm{X}-100$ and $10 \%$ FBS in $\mathrm{PB}, \mathrm{pH} 7.2$, for $30 \mathrm{~min}$ at $4^{\circ} \mathrm{C}$. Subsequently, cells were incubated in anti-microtubuleassociated protein 2 (MAP2)a,b (1:500; Chemicon), anti-GFAP (1:500; Dako, Glostrup, Denmark), and anti-O4 (1:500; Chemicon) antibodies for $12 \mathrm{hr}$ at $4^{\circ} \mathrm{C}$. Cells were then incubated in a tetramethylrhodamine isothiocyanate-conjugated anti-mouse IgG antibody (1:200; Sigma), an FITCconjugated anti-rabbit IgG antibody (1:200; Sigma), and a 7-amino-4methylcoumarin-3-acetic acid-conjugated anti-mouse IgM antibody (1:200; Sigma) for $2 \mathrm{hr}$ at room temperature. The cell typing was performed using a fluorescent microscope (Nikon, Tokyo, Japan).

Cell death counting. Total cell death in the culture with or without $\mathrm{Ng} 1$ was examined after 0,2 , and $4 \mathrm{~d}$ of administration. Cells were fixed in $4 \%$ paraformaldehyde in $\mathrm{PB}, \mathrm{pH} 7.2$, for $10 \mathrm{~min}$ at room temperature and then incubated in $0.12 \mu \mathrm{g} / \mathrm{ml}$ Hoechst 33258 (Nacalai Tesque) in $\mathrm{PB}, \mathrm{pH} 7.2$, for 15 min at room temperature. Living and dead cells, which bore shrunken nuclei, were counted using the fluorescent microscope. Subsequently, astrocytic cell death in the culture with or without $\mathrm{Ng} 1$ after $2 \mathrm{~d}$ of administration was evaluated. Cells were fixed in $4 \%$ paraformaldehyde in $\mathrm{PB}, \mathrm{pH} 7.2$, for $30 \mathrm{~min}$ at $4^{\circ} \mathrm{C}$ and treated for permeation in $0.5 \%$ Triton $\mathrm{X}-100$ and $10 \%$ FBS in $\mathrm{PB}, \mathrm{pH} 7.2$, for $30 \mathrm{~min}$ at $4^{\circ} \mathrm{C}$. Cells were then incubated in an anti-GFAP antibody (1:500) for $12 \mathrm{hr}$ at $4^{\circ} \mathrm{C}$ and incubated further in an FITC-conjugated anti-rabbit IgG antibody (1:200) for $2 \mathrm{hr}$ at room temperature. Finally, cells were incubated in $0.12 \mu \mathrm{g} / \mathrm{ml}$

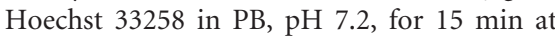
room temperature. GFAP-positive and shrunken-nucleus-bearing dead astrocytes were counted using the fluorescent microscope.

The protein synthesis and administered reagent. The coding region of Ng1 cDNA lacking BMP-binding modules was cloned using Mutan-Super Express Km (Takara). Subsequently, the cDNA coding Ng1 or Ng1 mutant was ligated to the expression vector $\mathrm{CXN} 2$, and the vector was then transfected to COS-7 cells in Opti-MEM I reduced-serum medium (Invitrogen) using Lipofectamine Plus Reagent (Invitrogen). The cells were maintained for $48 \mathrm{hr}$, and the culture medium was harvested. Finally, the secreted $\mathrm{Ngl}$ or $\mathrm{Ngl}$ mutant protein was purified from the culture medium using Microcon filter units (Millipore, Bedford, MA) according to the protocol of the manufacturer. For the control, the vector was solely transfected to COS-7 cells, and the equally processed culture medium was used. Neural stem cells were incubated in DMEM-F12 containing 50 $\mathrm{ng} / \mathrm{ml} \mathrm{Ng1} \mathrm{or} \mathrm{Ng1} \mathrm{mutant} \mathrm{protein.} \mathrm{Subse-}$ quently, $10 \mathrm{ng} / \mathrm{ml} \mathrm{BMP-4} \mathrm{(Wako,} \mathrm{Osaka,} \mathrm{Ja-}$ pan) was administered to the culture.

Tissue culture preparation. The hippocampus, cerebellum, spinal cord, and meninges were dissected from a P14 Wistar rat and digested in papain solution (Worthington, Lakewood, NJ) for $30 \mathrm{~min}$. Then the tissues were mechanically dissociated using a Pasteur pipette. Next, $5 \times 10^{6}$ cells were incubated in DMEM low glucose (Invitrogen) containing $10 \%$ FBS for $3 \mathrm{~d}$ at $37^{\circ} \mathrm{C}$ and incubated further in serum-free DMEM for $24 \mathrm{hr}$ at $37^{\circ} \mathrm{C}$. Finally, the culture supernatan was harvested for use.

The administration of anti-Ng1 antibody and the oligopeptide antigen. The purified anti-Ng1 antibody was solved in PB, pH 7.2, and antibody (50 $\mu \mathrm{g} / \mathrm{ml}$ ) was administered. For the neutralization, synthesized oligopeptide antigen of anti-Ng1 antibody $(50 \mu \mathrm{g} / \mathrm{ml})$ was used. For the control, 10\% normal rabbit serum was administered.

\section{Results}

The cloning of Neurogenesin-1 cDNA from adult hippocampal astrocytes and its characteristic structure To clone astrocyte-derived factors interacting with BMPs, we prepared reverse transcripts from mRNA of adult hippocampal astrocytes. Referring to proposed BMP-binding modules in chor- 
din (Sasai et al., 1994; Larrain et al., 2000), we designed degenerate PCR primers and cloned a fragment of cDNA. The amplified product was subjected to $5^{\prime}$ and 3' RACE for elongation, and subsequently, an oligocapping method was applied for additional cloning of $5^{\prime}$ end. As a result, we cloned the 3893 bp full-length cDNA of a novel astrocyte-derived factor, Neurogenesin-1 (after neurogenesis) (GenBank accession number AB080636). The coding region of cDNA was $1566 \mathrm{bp}$, and the expected molecular weight of its coding protein was $\sim 50$ $\mathrm{kDa}$. Ng1 contained a putative signal peptide in its $\mathrm{N}$ terminus and three cysteine-rich domains that shared similarities with chordin (Fig. 1a,b). Northern blot analysis indicated a $3.9 \mathrm{~kb}$ transcript in adult hippocampal astrocytes (Fig. 1c).

Ng1 antagonizes BMP-4 and causes dorsalization of ventral ectoderm consistent with its shared structural feature among BMP-4 antagonists

The cysteine-rich domains contained in Ng1 suggested its potential function in the dorsalization of ectoderm, as was proposed in chordin or other BMP-4 antagonists. To explore the function of $\mathrm{Ng1}$, in vitro synthesized capped mRNA-encoding Ng1 was microinjected into the ventral blastomere of Xenopus embryos at the eight cell stage. As a consequence, the secondary dorsal axes forming at the site of injection were observed at high frequency by the expression of $\mathrm{Ng} 1$. When $\mathrm{Ng} 1$ mRNA (1.6 ng of RNA per embryo) was injected, $60 \%$ of the surviving embryos had a partial secondary dorsal axis at the tadpole stage (Fig. 2a). This effect was dose dependent such that the frequency of this phenotype rose as the amount of injected RNA increased (Table 1). Complete sec-

ondary axes with eyes were not detected in any microinjected embryo, although a few embryos showed secondary axes containing a cement gland as shown in Figure $2 b$. Histological analysis verified that the dorsal tissues in the secondary axis contained the notochord, somites, and neural tube, as shown in Figure $2 c$. This result indicates that $\mathrm{Ng} 1$ contributes to induction of a dorsal structure through binding to BMP-4.

\section{Ng1 mRNA is preferentially expressed in neurogenic regions throughout brain development}

To investigate the implication of $\mathrm{Ng} 1$ in neurogenesis, its spatial and temporal expression patterns in the brain were examined using in situ hybridization. In the embryonic brain (at E17), Ng1 mRNA was intensely expressed in ventricular zones and also in the retina, where vigorous neurogenesis takes place (Fig. $3 a$ ). In later development, this abundant expression was gradually confined to the dentate gyrus of the hippocampus and the subventricular zone adjacent to the lateral ventricle (Fig. 3b,c). Weak signals were also observed throughout the brain (Fig. 3b,c). Additional intense expression was found along the rostral migratory
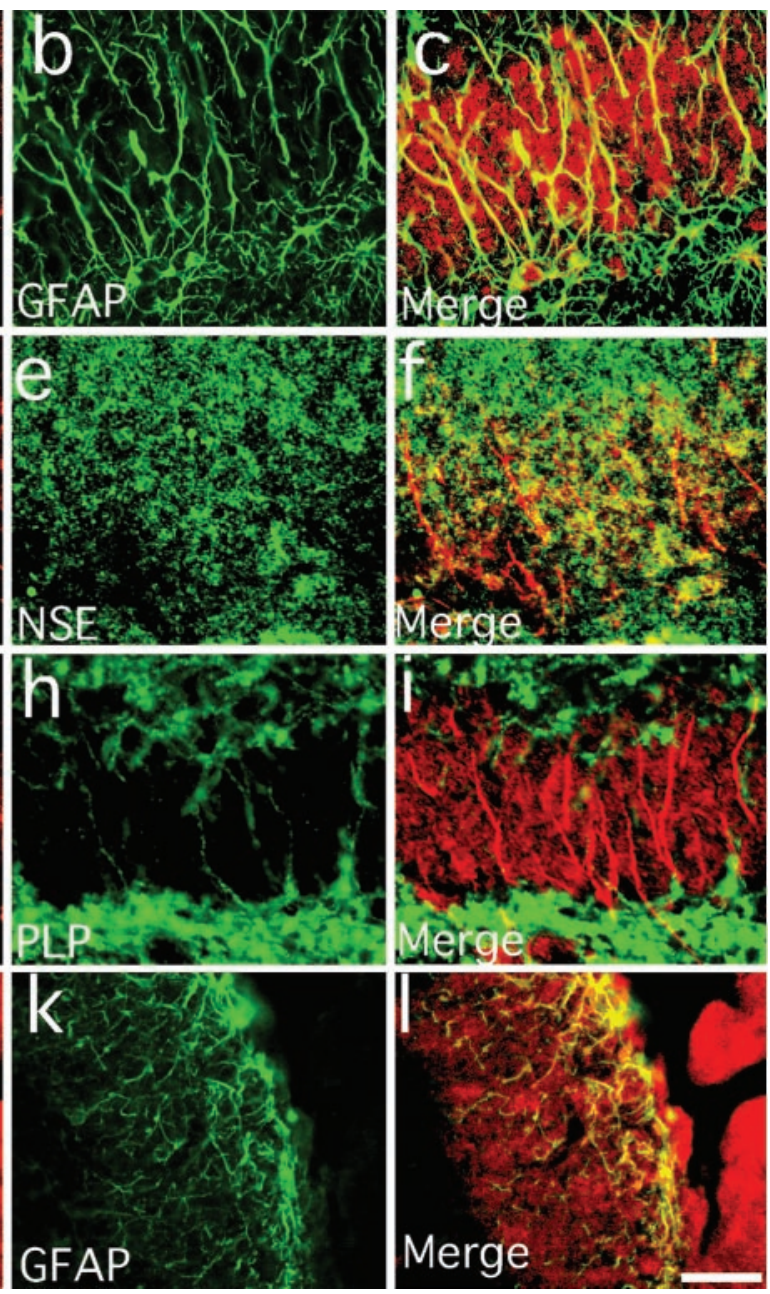

Figure 4. $\mathrm{Ng} 1$ is intensely expressed in adult brain neurogenic regions. $a-i$, Double labeling showing cellular characterization of $\mathrm{Ng1}$-positive cells in the dentate gyrus of the adult hippocampus. Note that GFAP-positive astrocytes in the granular cell layer of the dentate gyrus abundantly express $\mathrm{Ng} 1(a-c)$. Double labeling by anti-Ng1 $(d)$ and anti-NSE $(e)$ antibodies also showed that

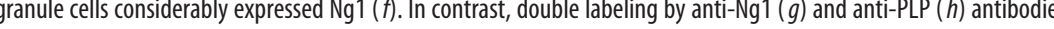
in the subventricular zone of the adult rat brain. Note that $\mathrm{Ng} 1$ is intensely expressed in GFAP-positive astrocytes in the subventricular zone. In addition, the choroidal plexus also expresses $\mathrm{Ng} 1$. ch, Choroidal plexus; $G r$, the granular layer of the dentate gyrus; LV, lateral ventricle; SVZ, subventricular zone. Scale bar, $100 \mu \mathrm{m}$.

stream in postnatal brains (Fig. 3b,c) (Lois et al., 1996). Interestingly, high-magnification images confirmed that Ng1 mRNA expression in the dentate gyrus of the hippocampus, where neurogenesis persists until adulthood, gradually increased with development (Fig. 3d-g). There was also considerable expression in the subventricular zone and the hippocampal CA1 region (Fig. $3 d-g)$. Bright-field observation revealed that Ng1 mRNA was intensely expressed by small-sized glial-like cells in the adult cerebral cortex (Fig. 3d).

$\mathrm{Ng} 1$ is prominently expressed in the hippocampal subgranular zone of the adult brain

We subsequently examined the cell type expressing Ng1 in the adult brain. We performed immunohistochemistry using antibody raised against Ng1, anti-GFAP (astrocyte marker) antibody, anti-NSE (neuronal marker) antibody, and anti-myelin PLP (oligodendrocyte marker) antibody. Double labeling by anti-Ng1 (Fig. 4a) and anti-GFAP (Fig. 4b) antibodies revealed that cells intensely expressing $\mathrm{Ng} 1$ in the granule cell layer of the adult hippocampus were mainly astrocytes (Fig. $4 c$ ). Double labeling 
a
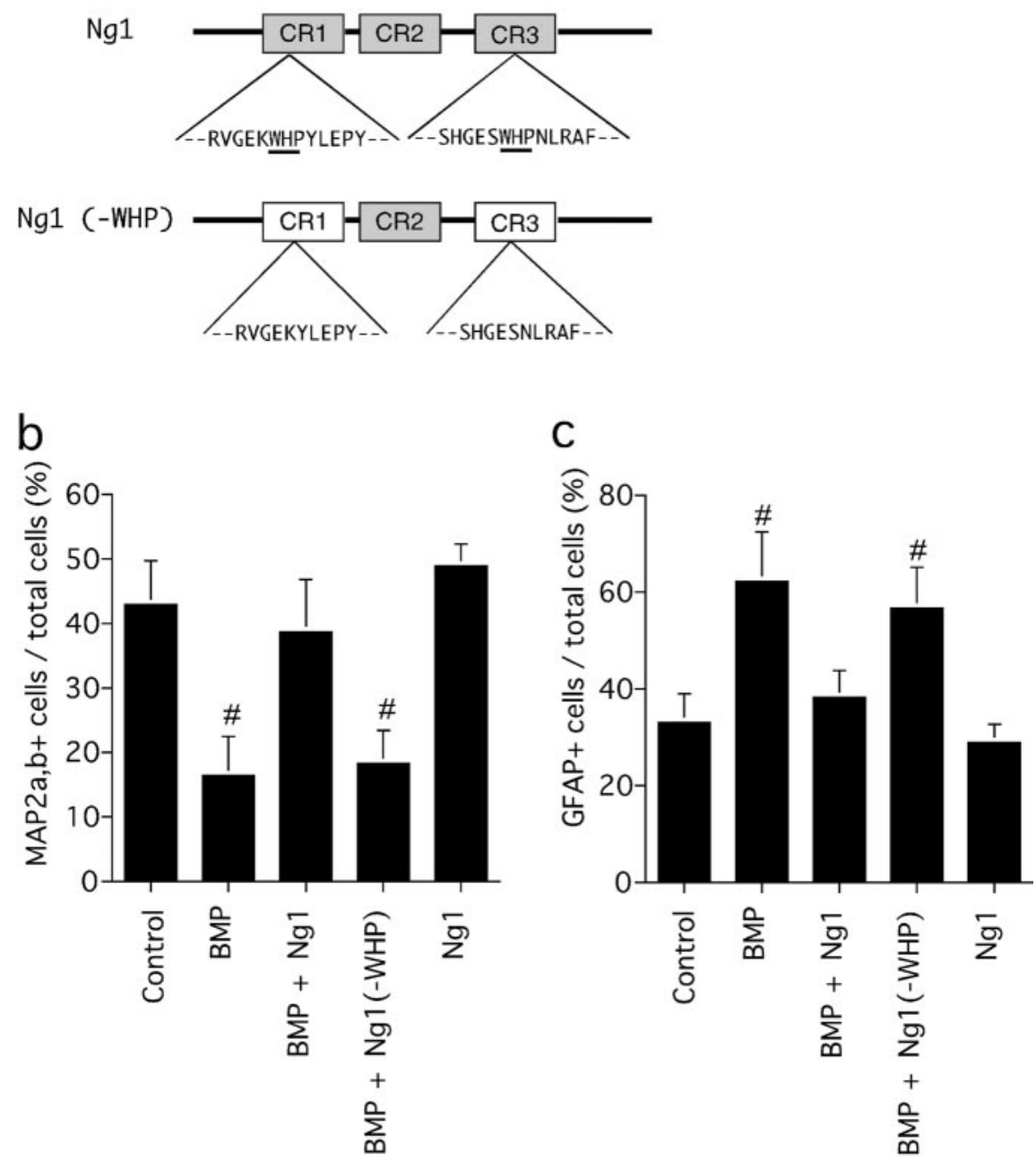

Figure 5. a, The schema of mutagenesis in $\mathrm{Ng1}$. BMP-binding modules in the first and third cysteine-rich domains (CR1 and CR3) of $\mathrm{Ng} 1$ (amino acid sequences, WHP) were genetically deleted. The bottom panel, $\mathrm{Ng} 1$ (-WHP), shows the Ng1 mutant lacking BMP-binding modules. $\mathrm{Ng} 1$ results in the direction of neurogenesis $(b)$ and the blockade of gliogenesis $(c)$. Control, Culture in the basal medium; BMP, neural stem cell culture incubated solely in BMP-4; BMP $+\mathrm{Ng} 1$, culture preincubated in $\mathrm{Ng} 1$ before the administration of BMP-4; BMP + Ng1(-WHP), culture preincubated in Ng1 (-WHP) before the administration of BMP-4; Ng1, culture incubated solely in Ng1. Error bars represent the mean \pm SEM of four replicates. ${ }^{*} p<0.05$.

were transfected with the expression vector CXN2, including $\mathrm{Ng1}$ or $\mathrm{Ng1}$ mutant cDNA. Each was administered to the neural stem cell culture prepared from the P35 rat hippocampus and preincubated for $3 \mathrm{hr}$. Subsequently, BMP-4 was added to the culture systems, and they were incubated further for $4 \mathrm{~d}$. After incubation, the ratios of the neuronal marker (MAP2a,b positive) and astrocyte marker (GFAP positive) were quantified. As a result, Ng1 significantly increased the ratio of MAP2a,b-positive neurons, whereas the ratio of GFAP-positive astrocytes decreased (Fig. 5b,c). In contrast, Ng1 lacking BMP-binding modules did not significantly increase the ratio of MAP2a,bpositive neurons but increased the ratio of GFAP-positive astrocytes, as was seen in BMP-4 solely administered culture (Fig. $5 b, c)$. These results indicated that $\mathrm{Ng} 1$ binding to BMP-4 interfered with its function and resulted in the glial fate adoption of neural stem cells. Sole administration of Ng1 slightly increased the ratio of MAP2a,bpositive neurons and instead decreased the ratio of GFAP-positive astrocytes.

Hoechst nuclear staining indicated that Ng1 did not significantly affect the survival of cells after 0, 2, and $4 \mathrm{~d}$ (Fig. $6 a$ ). To examine the possibility that $\mathrm{Ng} 1$ induces astrocyte-specific cell death and as a result decreases the ratio of astrocytes, the ratio of dead astrocytes in the culture with or without Ng1 after $2 \mathrm{~d}$ was quantified (Fig. 6b). The results showed that astrocytic cell death was not induced by Ng1, suggesting that the reduction in the ratio of astrocytes by $\mathrm{Ng1}$ was not caused by the specific killing of astrocytes but may be caused by the neuronal fate adoption of neural stem cells.

\section{Ng1 provides neurogenic cues for neural stem cells residing in the adult hippocampus}

by anti-Ng1 (Fig. $4 d$ ) and anti-NSE (Fig. 4e) antibodies showed that dentate granule cells also considerably expressed Ng1 (Fig. $4 f$ ). In contrast, double labeling by anti-Ng1 (Fig. $4 g$ ) and antiPLP (Fig. 4h) antibodies showed that Ngl was not detected in oligodendrocytes (Fig. 4i). Additional immunocytochemical analysis showed that Ng1 was also expressed in astrocytes residing in the subventricular zone of the lateral ventricle (Fig. $4 j-l$ ). Anti-Ng1 antibody staining additionally revealed expression of Ng1 in choroidal plexus (Fig. 4j). These results suggest that astrocytes in the hippocampal dentate gyrus, where adult neurogenesis occurs persistently, mainly express Ng1 in abundance, and are implicated in neurogenic environmental cues in the adult brain.

Ng1 antagonizes BMP-4 and results in neuronal fate adoption of hippocampal neural stem cells

Because of the abundant expression of BMPs in the adult hippocampus, we examined the role of $\mathrm{Ng} 1$ in adult neurogenesis in vitro. Ng1 or Ng1 mutant lacking BMP-binding modules (Fig. $5 a$ ) was derived from the culture supernatant of COS-7 cells that
The neurogenic activity of Ng1 endogenously expressed in the hippocampus was then examined. We examined the neurogenic activity of various regions in the CNS, using the dissociated cultures of various CNS tissues. The culture supernatants were harvested after incubating tissues for $3 \mathrm{~d}$. We subsequently incubated P14 hippocampal neural stem cells in the various culture supernatants for $4 \mathrm{~d}$ and analyzed the ratio of MAP2a,b-positive neurons. The result showed that the hippocampal culture supernatant significantly increased the ratio of MAP2a,b-positive neurons compared with other supernatants (Fig. 7a). On the basis of these findings, we assessed the involvement of $\mathrm{Ng} 1$ in hippocampal neurogenic cues. The supernatant of dissociated hippocampal cultures from P14 rats was preincubated with anti$\mathrm{Ng} 1$ antibody for $2 \mathrm{hr}$ before the administration to neural stem cells. Neural stem cells were incubated further for $4 \mathrm{~d}$, and the ratios of MAP2a,b-positive neurons and GFAP-positive astrocytes were quantified. Consequently, the ratio of MAP2a,bpositive neurons significantly decreased in the culture supernatant pretreated with anti-Ng1 antibody (Fig. $7 b$ ), whereas the 


\section{a}

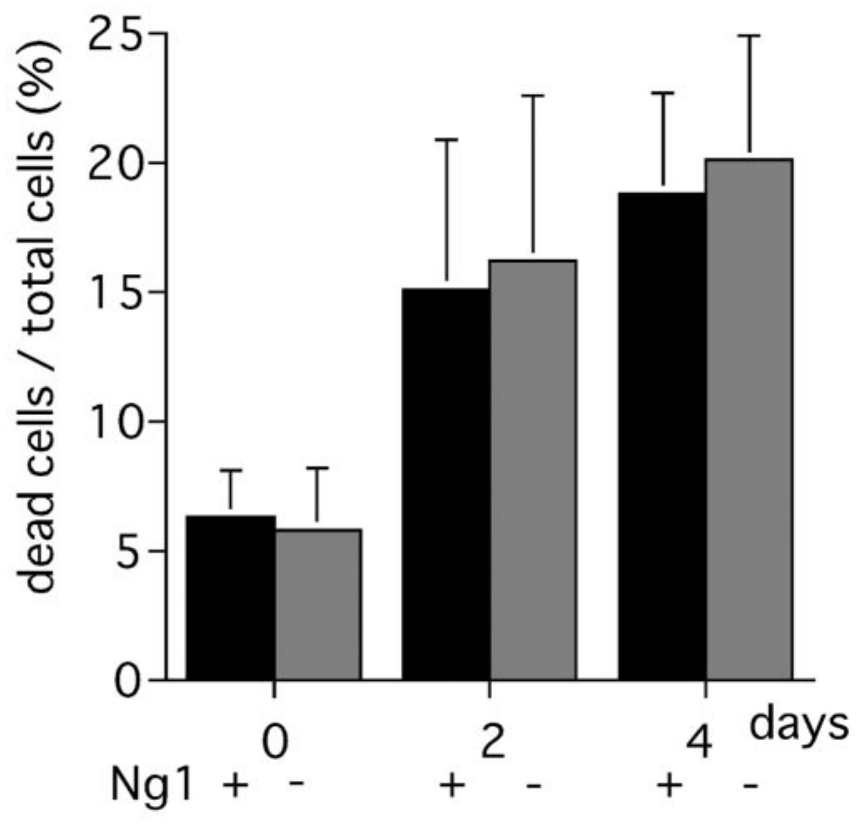

\section{b}

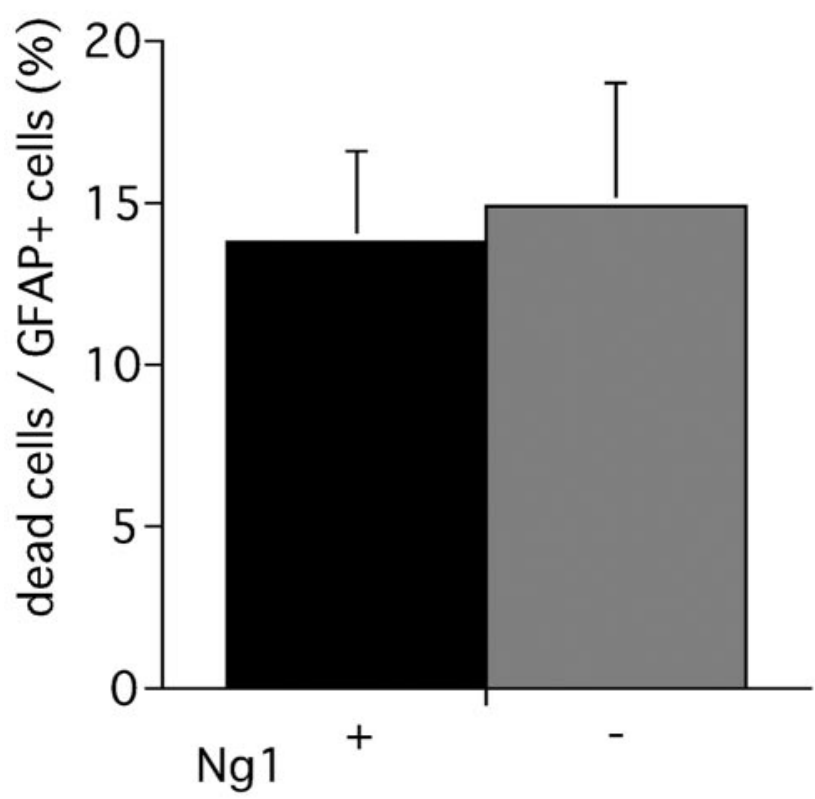

Figure 6. $\mathrm{Ng} 1$ did not significantly affect cell death. $a$, Cell death observed after 0,2 , and $4 \mathrm{~d}$ in the culture with or without $\mathrm{Ng} 1 . b$, Astrocytic cell death after $2 \mathrm{~d}$ in the culture with or without $\mathrm{Ng} 1$. Error bars represent the mean \pm SEM of five replicates.

ratio of GFAP-positive astrocytes increased. These results indicated that anti-Ng1 antibody suppressed the neurogenic activity in the supernatant of dissociated hippocampal cultures, and that Ng1 was involved in the neurogenic cues in the hippocampus.

\section{Discussion}

The factors involved in adult hippocampal neurogenesis are only beginning to be understood. We cloned and characterized a new astrocyte-derived factor, $\mathrm{Ng} 1$, which appears to be involved in adult hippocampal neurogenesis. Ng1 contains an N-terminal signal peptide and three cysteine-rich domains and shares similarity with chordin, a BMP-4 antagonist (Abreu et al., 2002). The C-terminal segments were composed of amino acid sequences unique to $\mathrm{Ng} 1$. The structural features of $\mathrm{Ng} 1$ suggest the ability of $\mathrm{Ng} 1$ to bind to BMP-4 at the BMP-binding modules residing in cysteine-rich domains. Other potential functions that may be attributed to this characteristic segment remain to be elucidated.

The dorsalization of ventral ectoderm indicates that $\mathrm{Ng} 1$ binds to BMP-4 in the cysteine-rich domains and antagonizes it. The ability of $\mathrm{Ng} 1$ to influence formation of the secondary axis was less robust than in ventral ectoderm exposed to chordin. These differences in activity may come from another cysteinerich domain that chordin possesses in the $\mathrm{C}$ terminus, which provides stability to the chordin-BMP-4 complex, resulting in increased activity when compared with $\mathrm{Ng} 1$. The finding that Ng1 showed dorsalizing activity and was ubiquitously expressed in neurogenic regions of the embryonic brain suggests a crucial role for Ng1 in dorsoventral axis formation. Because other BMP antagonists have similar functions in dorsoventral axis formation, the unique functions of $\mathrm{Ng} 1$ can be attributed to the spatiotemporal expression pattern characteristic of $\mathrm{Ng} 1$.

The intense expression of $\mathrm{Ng} 1 \mathrm{mRNA}$ in the postnatal brain was gradually confined to the hippocampus and to the neighboring subventricular zone of the lateral ventricle, where adult neurogenesis persists. This spatiotemporal expression pattern of $\mathrm{Ng} 1$ indicates that $\mathrm{Ng} 1$ participates in the neurogenic environmental cues in these regions. The data also showed that $\mathrm{Ng} 1$ was expressed ubiquitously but moderately throughout the brain. As was reported recently, BMPs have been implicated in multiple aspects of neural development, including the proliferation and differentiation of neural progenitor cells (Mehler et al., 2000). $\mathrm{Ng} 1$ may function in the modulation of BMP activity. The immunocytochemical analysis in the adult brain showed that $\mathrm{Ng} 1$ was prominently expressed in the hippocampal dentate gyrus and the subventricular zone of the lateral ventricle, and this finding supports the theory that $\mathrm{Ng} 1$ participates in adult hippocampal neurogenesis as well.

The proposed implication of $\mathrm{Ng} 1$ in adult neurogenesis was examined further using the hippocampus-derived neural stem cell culture. Our data revealed that Ng1 antagonizes BMP-4 and alters the fate commitment of neural stem cells from gliogenesis to neurogenesis. We also confirmed that Ng1 lacking BMPbinding modules failed to induce neurogenesis. Previous reports that the ligand-binding activation of BMP receptor type II resulted in the glial fate adoption of the neural stem cell (Nakashima and Taga, 2002) might provide an explanation for our data. Because it was suggested recently that BMP signaling serves crucial functions for neuroplasticity and synaptic functions, it is possible that $\mathrm{Ng} 1$ may influence hippocampal plasticity by regulating the activity of BMPs. Additional analysis is required to elucidate the implication of $\mathrm{Ng} 1$ in neuron-glia interactions in the adult brain.

In the present study, we also demonstrated that the supernatant of dissociated hippocampal culture resulted in the neural commitment of neural stem cells, and that anti-Ng1 antibody antagonized the activity of the hippocampal culture medium. These results indicate that the hippocampal culture medium contained secreted $\mathrm{Ng1}$, and that $\mathrm{Ng} 1$ supplied neurogenic cues in the hippocampus. Because the structural feature in the $\mathrm{C}$ terminus of Ng1 was unique and did not share any similarities with other BMP antagonists, it might be possible that the unique se- 


\section{a}
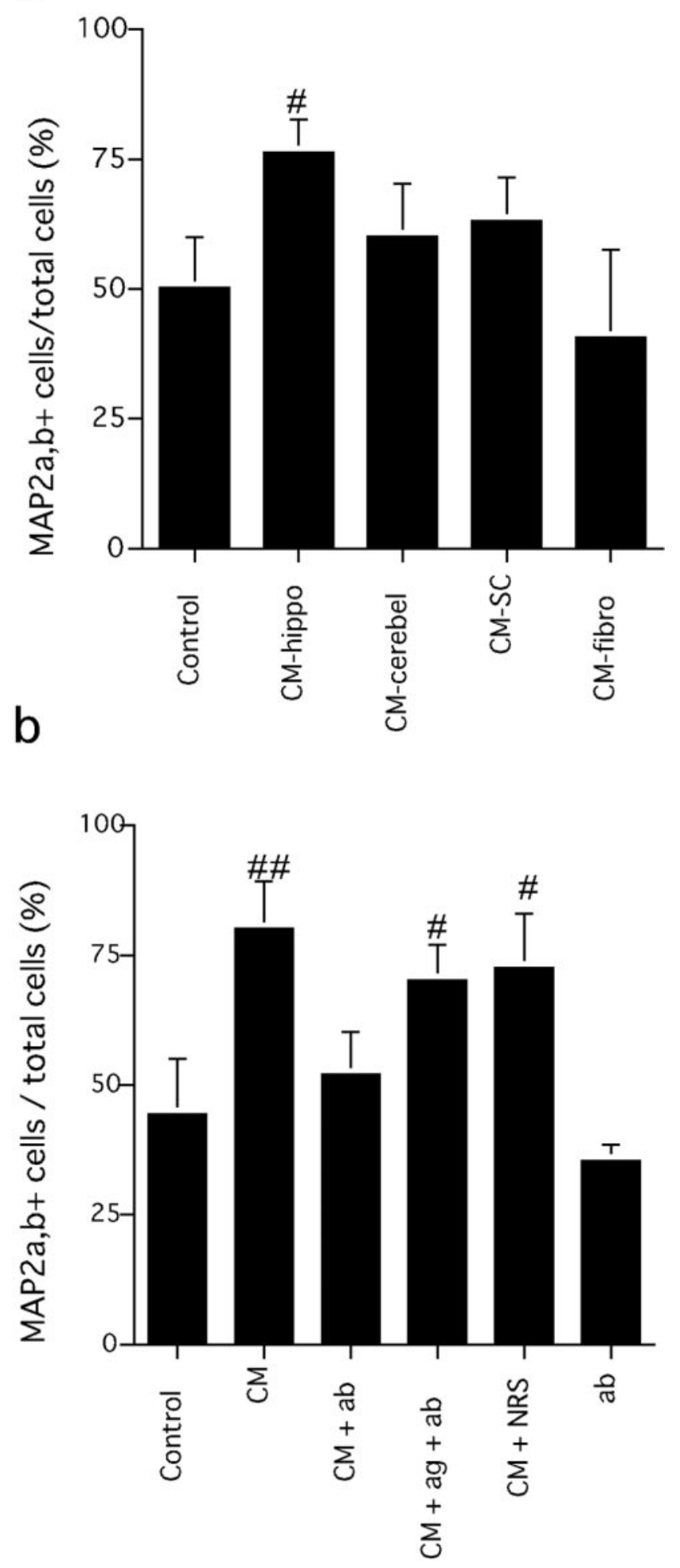

Figure 7. a, The neurogenic activity of various regions in the CNS. Control, basal culture medium; CM-hippo, the supernatant of dissociated hippocampal culture; CM-cerebel, the supernatant of dissociated cerebellar culture; CM-SC, the supernatant of dissociated spinal cord culture; CM-fibro, the supernatant of meningeal fibroblast culture. $b$, The inactivation of hippocampal neurogenic activity after the administration of anti-Ng1 antibody. Control, Culture incubated in the basal medium; CM, culture incubated in the culture supernatant; $\mathrm{CM}+\mathrm{ab}$, culture incubated in the culture supernatant preincubated with anti-Ng1 antibody; $\mathrm{CM}+\mathrm{ag}+\mathrm{ab}$, culture incubated in the culture supernatant, which was preincubated with antigen-treated anti-Ng1 antibody; CM + NRS, culture incubated in the culture supernatant preincubated with normal rabbit serum; ab, culture incubated in anti-Ng1 antibody. Error bars represent the mean \pm SEM of four replicates. ${ }^{*} p<0.05$; ${ }^{\# \#} p<0.01$. quence of Ng1 contributed to its neurogenic activity. Alternatively, Ng1 could interact with other neurogenic factors and indirectly contribute to neurogenesis. The recent studies showed that chordin bound to a secreted metalloproteinase, xolloid (Piccolo et al., 1997). These findings raised the possibility that $\mathrm{Ng} 1$ interacts with proteolytic enzymes that may be active in neurogenesis. Compared with the neurogenic activity resulting from the antagonization of BMP-4, this direct effect on neural stem cells seems to be more moderate, as was observed in Figure $5 b, c$. Together, the neurogenic activity of $\mathrm{Ng} 1$ is attributed to its ability to antagonize BMP-4 and to its intrinsic neurogenic activity.

Neurogenesis occurring in the adult hippocampus is considered to be crucial for the acquisition of learning and memory, but the neurogenic cues that generate the neural adoption of neural stem cells remain unknown. A recent study proposed that astrocytes were implicated in adult neurogenesis; however, the substance directing neurogenesis still remains to be elucidated (Song et al., 2002). To date, several kinds of mitogens, such as bFGF and epidermal growth factor, were exogenously administered to stimulate the proliferation of neural stem cells, and these were seemingly successful in replenishing degenerating neurons (Nakatomi et al., 2002). However, these mitogens were efficacious for various cells in the brain and could cause side effects. Our present study suggests that endogenous neurogenic cues might offer insights into the development and treatment of hippocampal neurodegeneration from a variety of insults.

\section{References}

Abreu JD, Coffinier C, Larrain J, Oelgeschlager M, De Robertis EM (2002) Chordin-like CR domains and the regulation of evolutionarily conserved extracellular signaling systems. Gene 287:39-47.

Banker GA, Cowan WM (1977) Rat hippocampal neurons in dispersed cell culture. Brain Res 126:397-425.

Ben-Arie N, Bellen HJ, Armstrong DL, McCall AE, Gordadze PR, Guo Q, Matzuk MM, Zoghbi HY (1997) Mathl is essential for genesis of cerebellar granule neurons. Nature 390:169-172.

Charytoniuk DA, Traiffort E, Pinard E, Issertial O, Seylaz J, Ruat M (2000) Distribution of bone morphogenetic protein and bone morphogenetic protein receptor transcripts in the rodent nervous system and upregulation of bone morphogenetic protein receptor type II in hippocampal dentate gyrus in a rat model of global cerebral ischemia. Neuroscience 100:33-43.

Ebendal T, Bengtsson H, Soderstrom S (1998) Bone morphogenetic proteins and their receptors: potential functions in the brain. J Neurosci Res 51:139-146.

Fode C, Gradwohl G, Morin X, Dierich A, LeMeur M, Goridis C, Guillemot F (1998) The bHLH protein Neurogenin2 is a determination factor for epibranchial placode-derived sensory neurons. Neuron 20:483-494.

Fujita S (1986) Transitory differentiation of matrix cells and its functional role in the morphogenesis of the developing vertebrate CNS. Curr Top Dev Biol 20:223-242.

Gage FH (2000) Mammalian neural stem cells. Science 287:1433-1438.

Gould E, Beylin A, Tanapat P, Reeves A, Shors TJ (1999) Learning enhances adult neurogenesis in the hippocampal formation. Nat Neurosci 2:260-265.

Gross RE, Mehler MF, Mabie PC, Zang Z, Santschi L, Kessler JA (1996) Bone morphogenetic proteins promote astroglial lineage commitment by mammalian subventricular zone progenitor cells. Neuron 17:595-606.

Guillemot F, Lo LC, Johnson JE, Auerbach A, Anderson DJ, Joyner AL (1993) Mammalian achaete-scute homolog 1 is required for the early development of olfactory and autonomic neurons. Cell 75:463-476.

Kanaka C, Ohno K, Okabe A, Kuriyama K, Itoh T, Fukuda A, Sato K (2001) The differential expression patterns of messenger RNAs encoding K-Cl cotransporters $(\mathrm{KCC} 1,2)$ and $\mathrm{Na}-\mathrm{K}-2 \mathrm{Cl}$ cotransporter (NKCC1) in the rat nervous system. Neuroscience 104:933-946.

Larrain J, Bachiller D, Lu B, Agius E, Piccolo S, De Robertis EM (2000) 
BMP-binding modules in chordin: a model for signaling regulation in the extracellular space. Development 127:821-830.

Lim DA, Tramontin AD, Trevejo JM, Herrera DG, Gracia-Verdugo JM, Alvarez-Buylla A (2000) Noggin antagonizes BMP signaling to create a niche for adult neurogenesis. Neuron 28:713-726.

Lois C, Garcia-Verdugo JM, Alvarez-Buylla A (1996) Chain migration of neuronal precursors. Science 271:978-981.

Ma Q, Kintner C, Anderson DJ (1996) Identification of neurogenin, a vertebrate neuronal determination gene. Cell 87:43-52.

Mehler MF, Mabie PC, Zhu G, Gokhan S, Kessler JA (2000) Developmental changes in progenitor cell responsiveness to bone morphogenetic proteins differentially modulate progressive CNS lineage fate. Dev Neurosci 22:74-85.

Nakashima K, Taga T (2002) Mechanisms underlying cytokine-mediated cell-fate regulation in the nervous system. Mol Neurobiol 25:233-244.

Nakashima K, Takizawa T, Ochiai W, Yanagisawa M, Hisatsune T, Nakafuku M, Miyazono K, Kishimoto T, Kageyama R, Taga T (2001) BMP2mediated alteration in the developmental pathway of fetal mouse brain cells from neurogenesis to astrocytogenesis. Proc Natl Acad Sci USA 98:5868-5873.

Nakatomi H, Kuriu T, Okabe S, Yamamoto S, Hatano O, Kawahara N, Tamura A, Kirino T, Nakafuku M (2002) Regeneration of hippocampal pyramidal neurons after ischemic brain injury by recruitment of endogenous neural progenitors. Cell 110:429-441.

Newport J, Kirschner M (1982) A major developmental transition in early Xenopus embryos. II. Control of the onset of transcription. Cell 30:687-696.

Piccolo S, Agius E, Lu B, Goodman S, Dale L, De Robertis EM (1997) Cleavage of chordin by xolloid metalloprotease suggests a role for proteolytic processing in the regulation of spemann organizer activity. Cell 91:407-416.

Sasai Y (2001) Regulation of neural determination by evolutionarily con- served signals: anti-BMP factors and what next? Curr Opin Neurobiol 11:22-26.

Sasai Y, Lu B, Steinbeisser H, Geissert D, Gont LK, De Robertis EM (1994) Xenopus chordin: a novel dorsalizing factor activated by organizerspecific homeobox genes. Cell 79:779-790.

Sasai Y, Lu B, Steinbeisser H, De Robertis EM (1995) Regulation of neural induction by Chd and Bmp-4 antagonistic patterning signals in Xenopus. Nature 376:333-336.

Soderstrom S, Bengtsson H, Ebendal T (1996) Expression of serine/threonine kinase receptors including the bone morphogenetic factor type II receptor in the developing and adult rat brain. Cell Tissue Res 286:269-279.

Song H, Stevens CF, Gage FH (2002) Astroglia induce neurogenesis from adult neural stem cells. Nature 417:39-44.

Sun Y, Nadal-Vincens M, Misono S, Lin MZ, Zubiaga A, Hua X, Fan G, Greenberg ME (2001) Neurogenin promotes neurogenesis and inhibits glial differentiation by independent mechanism. Cell 104:365-376.

Tanaka M, Wang DY, Kamo T, Igarashi H, Wang Y, Xiang YY, Tanioka F, Naito Y, Sugimura H (1998) Interaction of EphB2-tyrosine kinase receptor and its ligand conveys dorsalization signal in Xenopus laevis development. Oncogene 17:1509-1516.

Ueki T, Nakanishi K, Asai K, Okouchi Y, Isobe I, Eksioglu YZ, Kato T, Kohno K (1993) Neurotrophic action of gliostatin on cocultured neurons with glial cells. Brain Res 622:299-302.

Ueki T, Fujita M, Sato K, Asai K, Yamada K, Kato T (2001) Epidermal growth factor down-regulates connexin- 43 expression in cultured rat cortical astrocytes. Neurosci Lett 313:53-56.

Yanagisawa M, Takizawa T, Ochiai W, Uemura A, Nakashima K, Taga T (2001) Fate alternation of neuroepithelial cells from neurogenesis to astrocytogenesis by bone morphogenetic proteins. Neurosci Res 41:391396. 